\title{
Tissue Destruction Resulting from the Interaction of Cytotoxic T Cells and Their Targets ${ }^{a}$
}

\author{
DAVID STEINMULLER, ${ }^{b, c}$ JOHN D. TYLER, ${ }^{d}$ \\ MARY ELLEN SNIDER..$^{b, e}$ ROGER L. NOBLE, ${ }^{b}$ \\ BRUCE L. RISER ; HUNEIN F. MAASSAB, ${ }^{\prime}$ AND \\ STEPHEN J. GALLI ${ }^{h}$ \\ ${ }^{h}$ Department of Surgery. \\ University of Michigan Medical School \\ Ann Arbor, Michigan 48109 \\ "Department of Surgery and Medical Biology \\ University of Tennessee Medical Center \\ Knoxuille. Tennessee 37920 \\ Department of Pathology \\ University of Michigan Medical School \\ "Department of Epidemiology" \\ University of Michigan School of Public Health \\ Ann Arbor, Michigan 48109

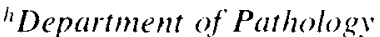 \\ Beth Israel Hospital and Harvard Medical School \\ The Charles A. Dana Research Institute \\ Beth Israel Hospital \\ Boston. Massachusetts 02215
}

The work reviewed here began as an attempt to examine the in vivo relevance of a group of cytotoxic $\mathrm{T}$ lymphocyte (CTL) clones directed against the then newly described histocompatibility $(\mathrm{H})$ antigen, epidermal alloantigen-1 (Epa-1). ${ }^{1} \mathrm{Be}$ cause, as its name implies. Epa-1 is preferentially expressed on epidermal cells (EC), as determined in cell-mediated cytotoxicity assays in vitro, ${ }^{2}$ we were particularly interested in determining whether Epa-1-specific CTL would attack allogeneic skin cells in vivo. Thus, we were gratified to find that relatively small numbers of clone 21-4, one of our most reliable Epa-1-specific clones, evoked full-thickness skin necrosis in an immunologically specific, major histocompatibility complex (MHC)-restricted, dose-dependent fashion upon intradermal inoculation into appropriate allogeneic hosts. . $^{3.4}$

The necrotic skin lesions that we initially evoked with clone $21-4,4$ and subsequently with several other Epa-1-specific CTL clones generated entirely in vivo, ${ }^{5}$ represent an intense form of the "immune lymphocyte transfer reaction." This reaction was first described in 1958 by Brent $e t a l .^{6}$ in the guinea pig and then

"This work was supported by U.S.P.H.S. Research Grants A121208, A123653. A122674. and AI23990 from the National Institutes of Health.

Present address: Dr. David Steinmuller. 352C Medical Laboratories. The University of Iowa. Iowa City, IA 52242.

"Present affiliation: T Cell Sciences. Inc., Cambridge, MA 02139. 
subsequently described by them ${ }^{7}$ and others ${ }^{8,9}$ in the rabbit. Billingham and Streilein's laboratory described this reaction in the hamster, ${ }^{10-12}$ rat, ${ }^{13}$ mouse, ${ }^{14,15}$ and $\operatorname{dog}{ }^{16}$ At the time of these reports, the effector cells for transfer reactions were crude suspensions of lymph node cells (LNC) and spleen cells (SC) from animals sensitized with a skin allograft, without any subsequent in vitro manipulation to boost alloimmunity. Consequently, reactions elicited with such cells rarely progressed beyond induration. By contrast, in our studies the lesions progressed to full-thickness necrosis. To determine whether this intense reaction reflected our use of cloned or in vitro-selected CTL, we tested the ability of cells sensitized in a classic or contemporary fashion to evoke transfer reactions in parallel in two inbred mouse strain combinations. For the classic test, we immunized hosts with

TABLE 1. Classic versus Contemporary Immune Lymphocyte Transfer Reactions

\begin{tabular}{|c|c|c|c|c|c|c|c|c|}
\hline \multirow[b]{3}{*}{ Day } & \multicolumn{8}{|c|}{ Reactions Grades $^{a}$} \\
\hline & \multicolumn{2}{|c|}{$\mathrm{C} 3 \mathrm{H} / \mathrm{He}$ Anti-CBA } & \multicolumn{6}{|c|}{$\mathrm{C} 3 \mathrm{H} / \mathrm{He}$ Anti-BALB/c } \\
\hline & $\mathrm{LNC}^{h}$ & $\overline{C T L}$ & \multicolumn{3}{|c|}{$\mathrm{LNC}$} & \multicolumn{3}{|c|}{$\mathrm{CTL}$} \\
\hline 1 & $1+1+$ & $3+3+$ & $1+d$ & $1+$ & $1+$ & $3+d$ & $3+3+$ & $3+$ \\
\hline 2 & $2+\quad 3+$ & $3+3+$ & $2+$ & $2+$ & $2+$ & $4+$ & $3+\quad 3+$ & $5+$ \\
\hline 3 & $2+4+$ & $4+5+$ & $2+$ & $1+$ & $2+$ & $5+$ & $4+4+$ & $5+$ \\
\hline 4 & $2+\quad 4+$ & $5+5+$ & $1+$ & $1+$ & $1+$ & $5+$ & $4+5+$ & $5+$ \\
\hline 5 & $2+\quad 4+$ & $5+5+$ & 0 & 0 & 0 & $5+$ & $5+5+$ & $5+$ \\
\hline 6 & $1+5+$ & $5+\quad 5+$ & 0 & 0 & 0 & $5+$ & $5+5+$ & $5+$ \\
\hline 7 & $4+5+$ & $5+5+$ & & & & & & \\
\hline 8 & $5+5+$ & $5+5+$ & & & & & & \\
\hline$\overline{\mathrm{CMC}^{e}}$ & 0 & $61 \%$ & & 0 & & & $91 \%$ & \\
\hline
\end{tabular}

${ }^{a} 0$, no perceptible response: $1+$, barely perceptible swelling: $2+$, swelling $3-4 \mathrm{~mm}$ in diameter, site soft; $3+$, swelling $\geq 5 \mathrm{~mm}$ in diameter, site firm; $4+$, large reaction with indurated core; $5+$, site ulcerated or necrotic. Grades shown are the highest of three injection sites per host, except for the two hosts that received $2.5 \times 10^{7}$ cells at a single site. Grading was performed daily $1-8$ days after injection of LNC or CTL.

${ }^{b}$ Draining lymph node cells (LNC) from skin-grafted hosts (classic test).

c In vitro-generated cytotoxic T lymphocytes (contemporary test).

${ }^{d}$ These two hosts received $2.5 \times 10^{7}$ cells; all others, $1 \times 10^{7}$ cells per site.

${ }^{e}$ Percent specific lysis of host-strain splenic lymphoblasts by effector LNC or CTL in $3 \mathrm{hr}$ chromium-release cytotoxicity assays at an effector-to-target-cell ratio of $25: 1$.

a single skin allograft and harvested LNC from draining lymph nodes; $;^{14}$ for the contemporary test, we primed hosts with an intraperitoneal inoculation of $1 \times 10^{7}$ allogeneic SC and then generated CTL from host SC in vitro in one-way mixed lymphocyte cultures. ${ }^{2}$

As seen in TABLE 1, the CTL evoked earlier and more intense transfer reactions than the $\mathrm{LNC}$ in both the $\mathrm{H}-2$-compatible $\mathrm{C} 3 \mathrm{H} / \mathrm{He}$ anti-CBA and the $\mathrm{H}-2-$ incompatible $\mathrm{C} 3 \mathrm{H} / \mathrm{He}$ anti-BALB/c strain combinations. The differences in the effectiveness of the CTL and LNC were particularly apparent in the latter combination, where the reactions evoked by the LNC never even became indurated, whereas all the reactions evoked by the CTL developed ulceration. In fact, we were surprised to find that the reactions induced by $\mathrm{LNC}$ in the $\mathrm{C} 3 \mathrm{H} / \mathrm{He}$ antiCBA strain combination eventually ulcerated, inasmuch as Streilein et al. ${ }^{13-15}$ did 
not observe reactions of this intensity in their original descriptions of murine transfer reactions. We used LNC obtained exclusively, however, from lymph nodes, draining the site of the sensitizing skin allograft, whereas Streilein et al. pooled LNC from draining and contralateral nodes (J. W. Streilein, personal communication). Regardless, our observations on the ability of allospecific CTL_-particularly those cloned from rejecting allografts and draining lymph nodes - to induce ulcerative transfer reactions demonstrate that allogeneic tissue can be destroyed through the direct mediation of CTL. This finding has clear relevance to the question of which $T$ cells mediate allograft rejection. ${ }^{17.18}$

More recently, we discovered that in certain contexts CTL also can mediate destruction of syngeneic tissue, ${ }^{19}$ apparently by initiating events that lead to an intense inflammatory reaction on the part of the host itself. This observation also has a precedent in the early work of Brent et al. ${ }^{7}$ They were interested in establishing that transfer reactions were provoked "by a local engagement of sensitized cells with antigen." To do this, they used normal hosts as "neutral soil for the interaction of antigen with sensitized cells." a principle previously established by those investigating the tuberculin reaction in the guinea pig. ${ }^{7}$ Thus, Brent et al. mixed sensitized A anti-B lymphoid cells (LC) with B cells and injected the mixtures into A hosts-hosts syngeneic to the effector cells; they reported feeble though significant cutaneous inflammatory reactions. Stronger reactions of this nature were described by Ramseier and Streilein. " who injected mixtures of sensitized host-strain LC and allogeneic LC or EC into the skin of irradiated hamsters. Once more, however, the reactions were never scored as necrotic, again presumably refiecting the use of unselected effector cell populations with a low frequency of specifically sensitized CTL.

We first evoked "innocent bystander" reactions with CTL directed against Epa-1. the previously mentioned tissue-restricted, non- $\mathrm{H}-2 \mathrm{H}$ antigen. well expressed on EC, fibroblasts, and activated macrophages, but poorly expressed, if at all, on LC. "2 Mixtures of Epa-1-specific bulk-culture or cloned CTL of strain $\mathrm{C} 3 \mathrm{H} / \mathrm{He}$ origin and Epa-1' strain CBA EC evoked grossly observable skin ulceration 3-5 days after injection into the skin of syngeneic $\mathrm{C} 3 \mathrm{H} / \mathrm{He}$ hosts. ${ }^{19}$ As seen in Figure 1. as few as $5 \times 10^{6}$ cloned CTL, mixed with an equal number of allogeneic EC. evokes an intense inflammatory reaction, with tissue necrosis extending from the panniculus carnosus to the epidermal surface. Clone NR46, which produced the lesion shown in the FIGURE. was derived from CTL generated entirely in vivo in EC-impregnated sponge-matrix allografts. "These Epa-1-specific clones are Lyt $-2^{\circ}$ and $\mathrm{L} \mathrm{T}^{-}$. as determined by flow cytometry ${ }^{5}$ - they express the classic phenotype of MHC class I-directed mouse CTL-and they lyse EC in vitro in an antigen-specific, $\mathrm{H}-2$-restricted, dose-dependent fashion. ${ }^{4,5}$

The transfer and bystander reactions in the Epa-1 and other CTL-target-cell systems we have studied to date have virtually the same kinetics. But as seen in Figure 2. the latter reactions are not as consistent as the former. For example, all of the Epa-1 transfer reactions ulcerated compared to $82 \%$ of the bystander reactions. Moreover. in contrast to transfer-reaction ulcers, which often exceed $5 \mathrm{~mm}$ in diameter, bystander-reaction ulcers are rarely more than $2 \mathrm{~mm}$ across, though the swelling and induration at the site often exceed $10 \mathrm{~mm}$. Nevertheless, the degree of tissue necrosis seen in bystander-reaction lesions (FIG. 1) is remarkable considering that the only source of specific antigen for the CTL are several million admixed target cells. Both transfer and bystander reactions are self-limiting, and the incidence of ulcerative lesions usually does not increase after five days. In the usual experiment, the ulcers heal within ten days after injection. Ulcers, however, may persist up to 15 days if the hosts are supplied with exogenous $\mathrm{T}$-cell growth 


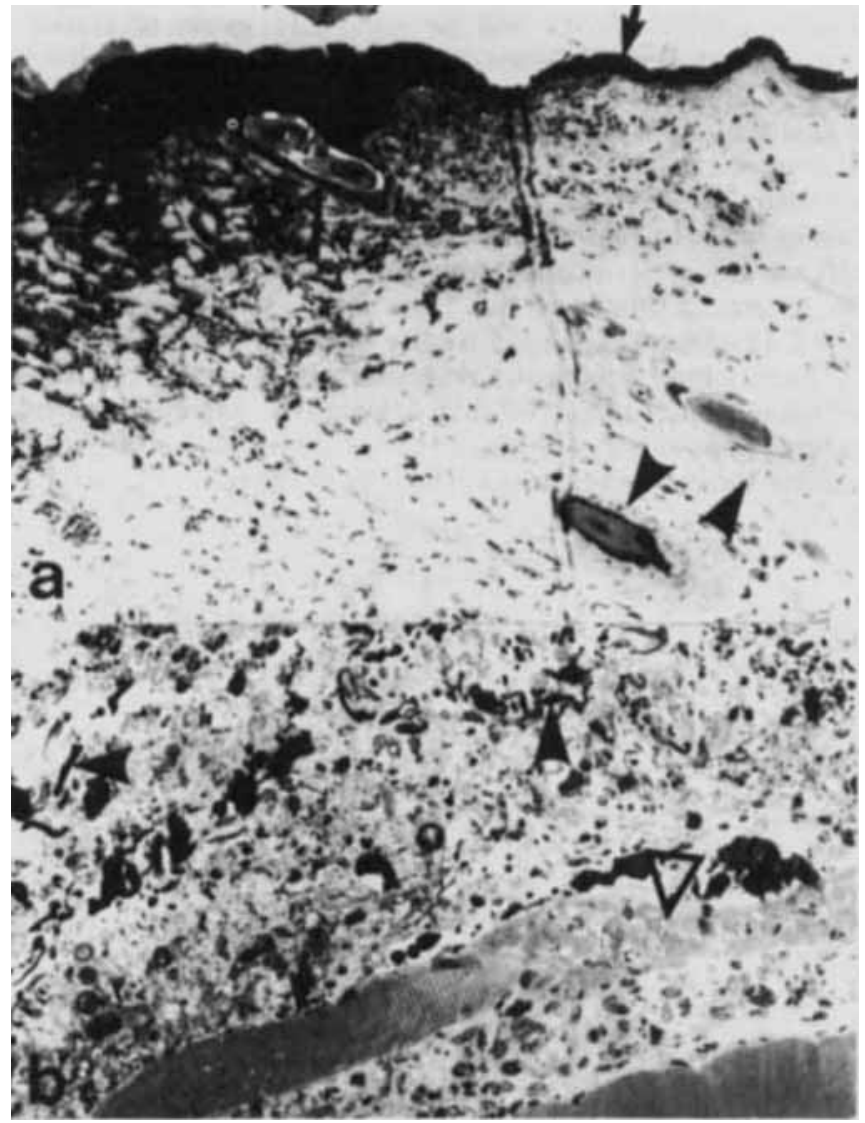

FIGURE 1. $\mathrm{C} 3 \mathrm{H} / \mathrm{He}$ mouse skin at the site of an intradermal injection three days earlier of $5 \times 10^{6} \mathrm{C} 3 \mathrm{H} / \mathrm{He}$ clone NR46 cytotoxic T lymphocytes (CTL) together with $5 \times 10^{6} \mathrm{CBA}$ epidermal cells ( $1 \mu \mathrm{m}$, Epon-embedded, Giemsa-stained sections). a: The solid arrow indicates the border between viable epidermis (extending to the right of the arrow) and necrotic epidermis (extending to the left of the arrow). The open arrowhead indicates a hair follicle within the region of necrotic dermis. Two viable hair follicles within the area of unaffected dermis are indicated by solid arrowheads $(\times 100)$. b: Site of injection of clone NR46 CTL and keratinocytes (some of the latter indicated by solid arrowheads) in the deep dermis. There is extensive inflammation. In addition, a skeletal muscle fiber of the panniculus carnosus exhibits focal necrosis (open arrowhead) as well as a region that appears viable (solid arrow) $(\times 250)$.

factor in the form of interleukin-2 (IL-2)-rich culture supernatants (data now shown). The dependence of the reactions on IL-2 is also evident from the finding that $1 \times 10^{6}$ Epa-1-specific CTL, which normally are too few to evoke ulcerative transfer reactions, do so when they are injected suspended in IL-2-rich supernatant fluid instead of conventional medium (data not shown).

FIgURE 2 also illustrates the specificity of the transfer and bystander reactions. Epa-1-specific CTL produce ulcerative transfer reactions in allogeneic CBA but 
not in syngeneic $\mathrm{C} 3 \mathrm{H} / \mathrm{He}$ hosts. and the same CTL evoke ulcerative bystander reactions when admixed with allogeneic $\mathrm{CBA} E \mathrm{EC}$ but not syngeneic $\mathrm{C} 3 \mathrm{H} / \mathrm{He} \mathrm{EC}$. CBA EC targets alone evoked grade $2+$ and $3+$ reactions that were most intense during the first day after injection. These transient reactions probably resulted from inflammation caused by stratum corneum antigens, ${ }^{21}$ because reactions of the same intensity were evoked by syngeneic $\mathrm{C} 3 \mathrm{H} / \mathrm{He} \mathrm{EC}$, and reactions evoked by injections of CBA LC alone were barely perceptible (data not shown).

Although we first described ulcerative transfer reactions with Epa-1 CTL, ${ }^{3-5}$ they are by no means limited to this $\mathrm{H}$-antigen system, but are evoked almost invariably by CTL directed against a variety of non- $\mathrm{H}-2$ and $\mathrm{H}-2$ antigens, as seen in TABLE 2. Surprisingly, bystander reactions with alloreactive CTL are evoked much more readily against non- $\mathrm{H}-2$ than against $\mathrm{H}-2$ antigens: we evoked ulcerative bystander lesions in only one of ten $\mathrm{H}-2$ incompatible compared to four of five H-2-compatible strain combinations. The lack of bystander reactivity of most of

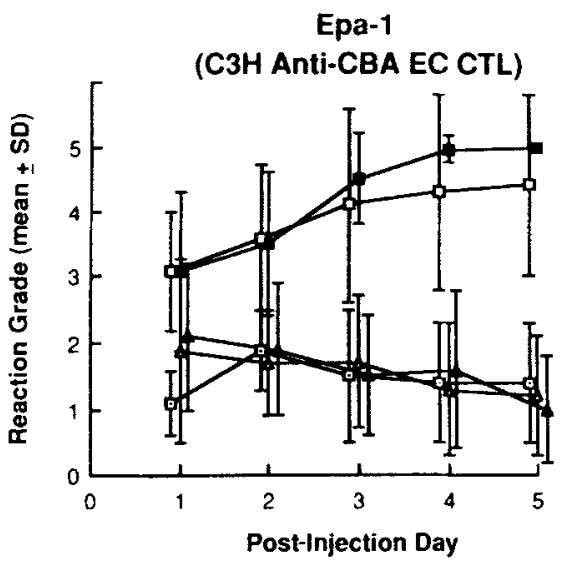

FIGURE 2. Kinetics of immune lymphocyte transfer and bystander reactions in the Epa-1 histocompatibility system. For reaction grades, see TABLE 1. CTL (C3H/He anti-CBA epidermal cells, EC) to CBA hosts $(-\square-, n=26)$ : CTL to C3H/He hosts $(-[-, n=26)$; CTL plus CBA EC to $\mathrm{C} 3 \mathrm{H} / \mathrm{He}$ hosts $(-\square-\mathrm{n}=33)$ : $\mathrm{CTL}$ plus $\mathrm{C} 3 \mathrm{H} / \mathrm{He} \mathrm{EC}$ to $\mathrm{C} 3 \mathrm{H} / \mathrm{He}$ hosts $(-\Lambda-, n=8):$ CBA EC alone to C $3 \mathrm{H} / \mathrm{He}$ hosts $\left(-\triangle_{-}, \mathrm{n}=12\right)$.

the H-2-specific CTL was unexpected given that these same CTL invariably produced $\mathrm{H}-2$-specific ulcerative transfer reactions. The defect does not seem to be due to an $\mathrm{H}-2$ Ir gene effect, $2-$ because the incidence of ulcerative bystander lesions evoked by DBA/2 and BALB/c CTL-both $\mathrm{H}-2^{d}$ - directed against the same C57BL/ 6 targets was $64 \%$ and $0 \%$, respectively. Nor can it simply be due to non-H-2 Ir gene effects: ${ }^{22}$ the incidence of ulcerative bystander lesions evoked by DBA/2 CTL directed against C57BL/6, BALB/c, and CBA targets was $64 \%$, $23 \%$, and $0 \%$, respectively (TABLE 2 ).

We think that mechanisms similar to those activated during intense delayedtype hypersensitivity (DTH) reactions may be responsible for the tissue destruction seen in bystander reactions (see below). If this is so, then the difficulty in evoking ulcerative bystander lesions with $\mathrm{H}-2$-specific CTL may reflect the wellestablished, though not well-appreciated, fact that non-H-2 antigens are actually 


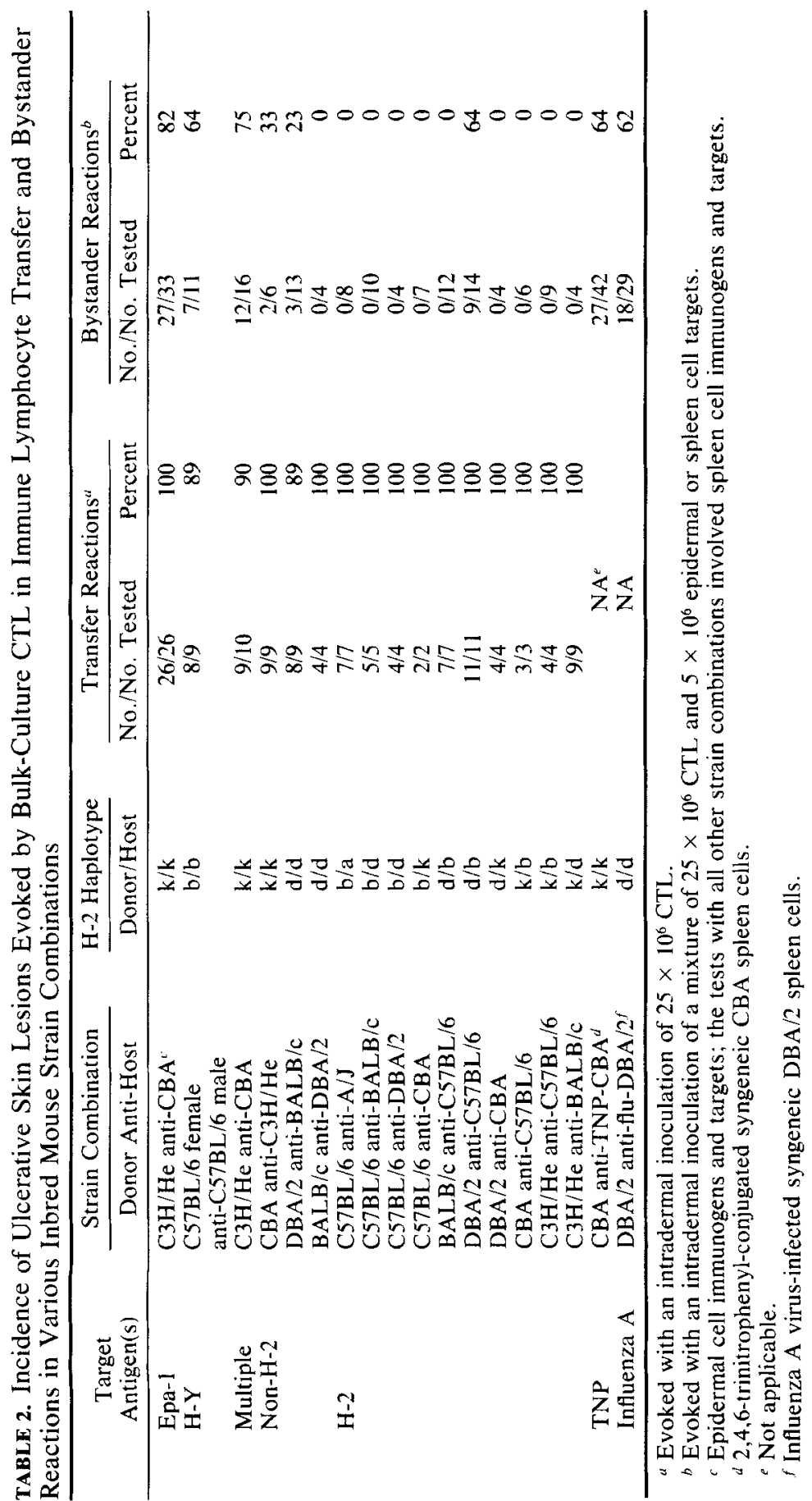


more effective than $\mathrm{H}-2$ antigens in evoking DTH. ${ }^{23-27}$ To explain this, Ohori et al. ${ }^{26}$ proposed that although $\mathrm{H}-2$ antigens represent a stronger stimulus, they also may provoke "a negative regulatory response, which the minor antigens escape." This could be the induction of suppressor $T$ cells $\left(T_{3}\right)$. It is important to reemphasize. however. that the same $\mathrm{H}$-2-specific CTL consistently evoke ulcerative transfer reactions in $\mathrm{H}-2$-incompatible strain combinations where they fail to evoke bystander reactions. But, in contrast to the latter reactions, where the admixed target cells represent a very limited source of alloantigen, in transfer reactions, where CTL are injected directly into allogeneic skin, alloantigen essentially is unlimited. The latter situation may result in much less pervasive downregulation by $T_{3}$. The hypothesis that $T_{S}$ dominate bystander reactions in $\mathrm{H}-2$ but not in non-H-2 antigen systems is testable, and experiments along these lines currently are in progress. For example, we are determining the effect of combining $\mathrm{H}-2$ and non-H-2 CTL-target-cell mixtures in the same inoculum and whether $\mathrm{T}$, actually are present in strain combinations where CTL-target-cell mixtures fail to evoke bystander reactions.

The capacity to initiate ulcerative bystander reactions is not limited to alloreactive CTL but also is a characteristic of CTL directed against hapten-modified and virus-infected target cells in totally syngeneic systems. Our observations in these systems, fully described elsewhere, ${ }^{28}$ are summarized at the bottom of TABLE 2. Mixtures of specifically sensitized CTL and trinitrophenyl-modified or influenza $A$ virus-infected syngeneic SC evoked necrotic. ulcerative bystander lesions in the skin of syngeneic hosts with a similar incidence to those evoked by alloreactive CTL directed against non- $\mathrm{H}-2$ antigens. Thus, bystander reactions are not peculiar to CTL specific for $\mathrm{H}$ antigens but appear to be a general manifestation of CTL-target-cell interactions in non-MHC systems.

A fundamental characteristic of the $T$-cell receptor is its ability to recognize antigen only when the antigen is associated on the cell surface with a molecule encoded by the MHC, ${ }^{2 y}$ the $\mathrm{H}-2 \mathrm{~K}^{k}$ gene product in the case of Epa-1. ${ }^{30}$ Thus, we previously established that the capacity of both bulk-culture and cloned Epa-1specific CTL to lyse $\mathrm{EC}$ in vitro and to evoke transfer reactions in vivo shows the identical H-2 restriction specificity. ${ }^{3-5}$ For example, clone 21-4 CTL evoke ulcerative lesions in the skin of $\mathrm{H}-2 \mathrm{~K}^{\mathrm{k}} \mathrm{B} 10$. A and B10. BR hosts but not in the skin of $\mathrm{H}$ $2 \mathrm{~K}^{\mathrm{b}} \mathrm{B} 10 . \mathrm{MBR}$ and $\mathrm{H}-2 \mathrm{~K}^{\mathrm{d}} \mathrm{B} 10 . \mathrm{OL}$ hosts, ${ }^{4}$ even though all of these $\mathrm{H}-2$ congenic and recombinant strains on the $\mathrm{C} 57 \mathrm{BL} / 10$ background are Epa- $1^{+} .31$ Therefore, we were fascinated to observe that the capacity of Epa-1-specific CTL to evoke ulcerative bystander lesions is apparently not $\mathrm{H}-2$-restricted. ${ }^{19}$ For example. mixtures of $\mathrm{H}-2^{h} \mathrm{C} 3 \mathrm{H} / \mathrm{He} \mathrm{CTL}$ and $\mathrm{CBA}$ EC evoke ulcerative lesions in Epa- ${ }^{-}{ }^{-} \mathrm{H}_{-} 2^{\mathrm{b}}$ $\mathrm{C} 3 \mathrm{H}$.SW hosts as well as they do in $\mathrm{C} 3 \mathrm{H} / \mathrm{He}$ hosts. and $\mathrm{C} 3 \mathrm{H} / \mathrm{He} \mathrm{CTL}$ are just as capable of evoking ulcerative bystander reactions in syngeneic hosts when they are injected together with Epa- ${ }^{*}$. H-2 ${ }^{\dagger}$ C57BL/6 EC as with Epa- ${ }^{+}, \mathrm{H}-2^{k} \mathrm{CBA}$ EC. ${ }^{28}$ In fact, as seen in TABLE 3 , the current overall incidence of ulcerative bystander reactions evoked with $\mathrm{H}$-2-incompatible and-compatible target cells and hosts is virtually identical, whereas there is a marked difference in the incidence of transfer reactions in H-2-compatible and-incompatible hosts in the Epa-1 system. The substitution of $\mathrm{H}-2$-incompatible for $\mathrm{H}-2-$ compatible haptenmodified target cells did not significantly reduce the incidence of ulcerative bystander reactions in the trinitrophenyl (TNP) system, although the substitution of H-2-incompatible hosts did (TABLE 3). By contrast, although the data are incomplete, it appears that bystander reactions in the influenza A system do follow the rules of MHC restriction (TABLE 3). 
Because the associative recognition of antigen with an MHC gene product is such an important feature of the T-cell receptor, ${ }^{29}$ we are examining the apparent disregard for this in our bystander-reaction systems very critically. For example, the use of H-2-incompatible target cells and hosts in bystander-reaction systems runs the risk of stimulating local cutaneous host-versus-graft reactions against the foreign $\mathrm{H}-2$ antigens expressed by the CTL or admixed target cells, and we have preliminary evidence that such reactions apparently can give rise to ulcerative skin lesions in certain strain combinations (data not shown). In addition to this relatively trivial explanation of the nonrestricted appearance of bystander reactions, we also are examining the possibility that $\mathrm{H}$-2-compatible antigen-presenting cells (APC) in the host or in the cell inoculum might circumvent $\mathrm{MHC}$ restriction by presenting antigen shed from the admixed allogeneic target cells to the CTL. For example, when ulcerative skin lesions are evoked in $\mathrm{C} 3 \mathrm{H} / \mathrm{He}\left(\mathrm{H}-2^{\mathrm{k}}\right)$ hosts by mixing C57BL/6 $\left(\mathrm{H}-2^{\mathrm{b}}\right)$ instead of $\mathrm{CBA}\left(\mathrm{H}-2^{\mathrm{k}}\right) \mathrm{EC}$ with $\mathrm{C} 3 \mathrm{H} / \mathrm{He}$ anti-

TABLE 3. Major Histocompatibility Complex (H-2) Restriction Tests of Transfer and Bystander Reactions

\begin{tabular}{lcccc}
\hline & & \multicolumn{2}{c}{ No. of Ulcerative Skin Lesions/No. Tested (Percent) } \\
\cline { 3 - 5 } $\begin{array}{l}\text { Non-H-2 } \\
\text { Antigen }\end{array}$ & Reaction & H-2-Compatible & \multicolumn{2}{c}{ H-2-Incompatible } \\
\cline { 3 - 5 } System & System & Target Cells and Hosts & Target Cells & Hosts $^{b}$ \\
\hline Epa-1 & Transfer & $26 / 26(100)$ & NA $^{d}$ & $2 / 27(7)$ \\
& Bystander & $27 / 33(82)$ & $10 / 14^{e}(71)$ & $12 / 15(80)$ \\
TNPf & Bystander & $27 / 42(64)$ & $6 / 12^{g}(50)$ & $3 / 13^{h}(23)$ \\
Flu $^{i}$ & Bystander & $18 / 29(62)$ & $3 / 13^{\prime}(23)$ & $0 / 3$ \\
\hline
\end{tabular}

"In relation to the injected bulk-culture cytotoxic T lymphocytes (CTL).

${ }^{b}$ Hosts $\mathrm{H}-2-$ compatible in relation to the CTL.

"Admixed target cells (in bystander reactions) H-2-compatible in relation to the CTL.

"Not applicable.

e.7>p $>.5$ versus 27/33 (all $\mathrm{p}$ values from chi square tests with Yates` correction).

2,4,6-trinitrophenyl modified cells.

s. $7>\mathrm{p}>.5$ versus $27 / 42$.

". $.05>\mathrm{p}>.02$ versus $27 / 42$.

Influenza A-virus infected cells.

j.05>p > .02 versus $18 / 29$.

Epa-1 CTL, Epa-1 antigen shed by the C57BL/6 EC might be presented to the CTL by syngeneic APC. The fact that ulcerative bystander reactions in the Epa-1 system are evoked with syngeneic CTL-target-cell mixtures in $\mathrm{H}$-2-incompatible hosts (TABLE 3) indicates that if presentation of Epa-1 by host APC occurs, it occurs in nonrestricted fashion. Ulcerative bystander reactions, however, are usually not evoked in H-2-incompatible hosts in the TNP-hapten and influenzavirus systems (TABLE 3). Moreover, although we have evoked ulcerative bystander reactions with cloned Epa-1-specific CTL, all of the H-2-restriction tests of bystander reactivity in this antigen system were conducted with unpurified, bulk CTL populations that might have included macrophages or other APC. Thus, currently we also cannot dismiss the possibility that $\mathrm{H}$-2-compatible donor APC in bystander-reaction inocula present antigen shed from the admixed allogeneic target cell to the CTL. Van Loveren et al.. ${ }^{32}$ however, described a nonadherent 
Lyt-1 mouse $\mathrm{T}$-cell population that mediates an obligatory early component of DTH in non-MHC restricted fashion. If, as we suspect, mechanisms similar to those evoked in DTH are critical components of bystander reactions, lymphokines released during the initial CTL-target-cell interaction might activate these nonrestricted helper $\mathrm{T}$ cells, which in turn might release a cascade of cellular reactions ${ }^{33}$ that eventuate in tissue destruction. Currently, we are investigating all of these possible explanations (which unfortunately are not mutually exclusive) of the apparent lack of MHC restriction of bystander reactions in some of the antigen systems we have studied. (Both cloned ${ }^{4.5}$ and bulk-culture ${ }^{30}$ Epa-1-specific CTL are $\mathrm{H}-2-$ restricted in their ability to evoke transfer reactions.)

Regardless of whether they truly defy MHC restriction, bystander reactions, as well as transfer reactions, are quite relevant to the theme of this volume, the biology of cytotoxic $T$ cells and their role in disease. The destruction of allogeneic tissue in transfer reactions is clear evidence of the capacity of CTL to mediate allograft rejection. Thus, our demonstration that CTL, extracted and cloned from skin-cell-impregnated sponge-matrix allografts and from lymph nodes draining the sites of real skin allografts, destroy allogeneic skin' fulfills a form of Koch's postulates regarding CTL as mediators of allograft immunity ${ }^{17}$ and adds to the growing evidence that CTL with the murine equivalent of the CD8 phenotype effect the acute rejection of allografts by sensitized hosts. ${ }^{34,35}$ Our results should not be construed, however, as disputing a role in allograft rejection for other functionally distinct T lymphocytes, such as those with the CD4 (helper) phenotype that lyse target cells expressing class $\mathrm{II} \mathrm{MHC}$ antigens and that mediate DTH. ${ }^{17.18}$

As already indicated, the tissue destruction seen in transfer reactions appears to result directly from an attack by CTL upon the allogeneic tissue into which they are inoculated: the capacity of CTL to mediate an ulcerative transfer reaction is dose-dependent, antigen-specific, and MHC-restricted. ${ }^{3-5}$ By contrast, the destruction of "innocent cells" in bystander reactions appears to be mediated through nonspecific inflammatory cells and factors of host origin activated by the initial antigen-specific CTL-target-cell interaction. The evidence for this is twofold. First there is no detectable nonspecific cytotoxicity by Epa-1-specific CTL in vitro (the only CTL we have tested so far in this regard): the addition of increasing numbers of unlabeled ("cold") Epa- ${ }^{+}$EC target to cocultures of Epa1-specific CTL and ${ }^{51} \mathrm{Cr}$-labeled Epa-1- EC targets in reverse competitive ("coldtarget") inhibition assays does not increase the release of ${ }^{51} \mathrm{Cr}$ above the background for the latter targets. ${ }^{28}$ Second, supernatant fluid concentrated from cocultures of Epa-1-specific CTL and Epa-1 $1^{+}$targets has no detectable cytotoxic effect on Epa- $1^{-}$targets in vitro or when injected into the skin of Epa-1 ${ }^{-}$hosts. ${ }^{28}$ Although based on negative data, these findings suggest that soluble factors generated by the interaction of anti-Epa-I CTL and their antigen-specific targets apparently are not directly responsible for the destruction of bystander cells. Thus, we feel that the bystander phenomenon more likely reflects the contribution of host regulatory and inflammatory cells not present in the artificial microenvironment of in vitro cell-mediated cytotoxicity assays, ${ }^{27}$ which are activated and/or recruited at the site of inoculation of the CTL-target-cell mixture. These cells may in turn mediate nonspecific tissue destruction themselves, as would be expected of activated macrophages and natural killer cells, or indirectly, through the release of factors such as lymphotoxin, tumor necrosis factor, or toxic lysosomal enzymes. We suggest that this entire cascade of events might be triggered by lymphokine(s) released during the initial antigen-specific CTL-target-cell interaction. ${ }^{32.33}$ Presumably, the same series of events occurs in transfer reactions, raising the inter- 
esting question of the extent to which the nonspecific mechanisms activated in bystander reactions normally contribute to the tissue destruction observed in such settings as allograft rejection, tumor immunity, and viral infections.

The concept that innocent bystander cells and tissue can be damaged as a consequence of an immune response activated by the recognition of a specific antigen, although not widely appreciated, is not new. Thus, Mintz and Silvers ${ }^{36}$ elegant demonstration of the focal rejection of chimeric skin grafts from allophenic (tetraparental) donors composed of mixtures of syngeneic and allogeneic cells is generally regarded as definitive evidence of the specificity of allograft rejection. The evidence of nonspecific rejection in their study, however, is often overlooked: when the majority of the cells in the chimeric grafts were allogeneic, the entire grafts were rejected. In Mintz and Silvers' own words, "nonspecific necrosis can sometimes contribute to the death of the neighboring cells if enough target cells are originally implicated in the rejection." 36

But the latter findings do not constitute proof that the syngeneic elements of the grafts were rejected in an antigenically nonspecific manner. Dvorak et al. ${ }^{37}$ showed that the vasculature of split-thickness human skin allografts represents a critical target of the first-set rejection response. One might therefore postulate, as suggested by Dr. Don W. Mason (personal communication), that if the microvasculature of a chimeric graft was predominantly allogeneic, then the apparently "nonspecific" rejection seen in the Mintz and Silvers study ${ }^{36}$ might have been caused by an antigenically specific attack on the composite grafts' vasculature. On the other hand, Dvorak et al. ${ }^{37}$ also showed that the rejection of first-set human skin allografts is preceded by widespread damage of venules and arterioles in both the allograft itself and in the underlying recipient tissue, the latter certainly constituting an antigenetically nonspecific effect of the graft-rejection process. One of us observed very significantly increased contraction (presumably, a manifestation of tissue necrosis) of skin isografts taken from bone marrow chimeras, where the only targets of rejection were allogeneic "passenger leukocytes" (D. Steinmuller, unpublished observations). Similarly, Stuart et al ${ }^{38}$ observed unremitting, fatal uremia in bilaterally nephrectomized rats that received kidney isografts from allogeneic bone marrow chimeras.

Innocent bystander reactions are undisputed components of certain destructive graft-versus-host reactions in the skin, ${ }^{39}$ kidney, ${ }^{40}$ and small intestine ${ }^{41.42}$ and of intense DTH reactions to tuberculin and purified proteins ${ }^{43,44}$ For example, Holoshitz et al.$^{44}$ reported that injections of $\mathrm{T}$-cell lines specifically reactive with myelin basic protein or with purified-protein derivative evoked bystander encephalitis and arthritis, respectively, in mice. Niederkorn et al. observed that certain genetic disparities, ${ }^{45}$ and certain tumors, ${ }^{46}$ allogeneic or syngeneic tumors, respectively, transplanted to the anterior chamber of the mouse eye were rejected with minimal nonspecific damage to the globe; with others, acute inflammatory reactions produced massive bystander destruction of ocular tissue, resulting in blindness. The catastrophic, nonspecific form of rejection seemed to occur only when DTH was a prominent part of the immune response. ${ }^{46}$ Bystander damage also can account for the rejection of mixtures of two syngeneic tumors, only one of which elicits a strong cell-mediated immune response. ${ }^{47}$ In this model system, morphologic analysis indicates that rejection depends on bystander damage to the composite tumors' common vasculature. ${ }^{47}$

Our observation that ulcerative bystander reactions frequently occur when CTL interact with virus-infected target cells in syngeneic hosts also has clear implications for the histopathology of viral infections. For example, the widespread and frequently life-threatening results of cytomegalovirus (CMV) infection 
in transplant patients are well-known. ${ }^{48}$ Patients with the lethal CMV syndrome develop gastrointestinal hemorrhages, and CMV can be isolated from the sites of ulceration producing the hemorrhages. It is generally thought that a cytolytic effect of the virus itself causes the ulceration. ${ }^{48}$ Our findings suggest, however, that intense inflammatory reactions triggered when the host's own CTL destroy virus-infected autochthonous cells may contribute to the tissue damage.

\section{SUMMARY}

In vitro- and in vivo-generated cytotoxic T lymphocytes (CTL) specific for major and minor histocompatibility antigens evoked antigen-specific full-thickness skin necrosis when injected intradermally into allogeneic mice in a variety of strain combinations. In addition, CTL-target-cell mixtures injected intradermally into hosts syngeneic to the CTL also evoked destruction of host tissue. These "innocent bystander" reactions were evoked with alloreactive CTL as well as with CTL directed against hapten (TNP)-modified and virus (influenza A)-infected target cells. Unlike the direct reactions, the bystander reactions in histocompatibility-antigen systems occurred in spite of $\mathrm{H}-2$ incompatibility of the CTL, admixed target cells, and the hosts. One explanation for these results, currently under investigation. is that some bystander reactions may occur without $\mathrm{MHC}$ restriction. In aggregate, our findings indicate that nonspecific as well as antigenspecific reactions initiated by $C T L$-target-cell interactions may contribute to tissue destruction in allograft rejection, in severe forms of delayed-type hypersensitivity, and in certain viral infections.

\section{ACKNOWLEDGMENTS}

We are grateful to Kathryn A. Aker, James J. Camilleri, Laura B. Campolito, Ane K. Gardner, and Gina M. Toth for technical assistance and to Marjorie M. Fisher and Terry P. Calhoun for help in preparing the manuscript.

\section{REFERENCES}

1. Tyler, J. D. \& D. Steinmuller. 1982. Establishment of cytolytic T lymphocyte clones to epidermal alloantigen Epa-1. Transplantation 34: 140-143.

2. Tyler, J. D. \& D. Steinmuller. 1981. Cell-mediated cytotoxicity to non-MHC alloantigens on mouse epidermal cells. III. Epidermal-cell specific cytotoxic T lymphocytes. J. Immunol. 126: 1759-1763.

3. Tyler, J. D., D. Steinmullek, S. J. Galli \& K. G. Waddick. 1983. Allospecific graft-versus-host lesions mediated in MHC-restricted fashion by cloned cytolytic $T$ lymphocytes. Transplant. Proc. 15: 1441-1445.

4. Tyler. J. D.. S. J. Gal.t.., M. E. Snider. A. M. Dvorak \& D. Steinmuller. 1984. Cloned Lyt-2- cytolytic $\mathrm{T}$ lymphocytes destroy allogeneic tissue in vivo. J. Exp. Med. 159: 234-243.

5. Snider, M. E., L. Armstrong, J. L. Hudson \& D. Steinmuller. 1986. In vitro and in vivo cytotoxicity of $\mathrm{T}$ cells cloned from rejecting allografts. Transplantation 42: $171-177$.

6. Brent, L.. J. Brown \& P. B. Medawar. 1958. Skin transplantation immunity in relation to hypersensitivity. Lancet 2: 562-564. 
7. Brent, L., J. Brown \& P. B. Medawar. 1962. Quantitative studies on tissue transplantation immunity. VI. Hypersensitivity reactions associated with the rejection of homografts. Proc. R. Soc. London, Series B. 156: 187-209.

8. MannicK, J. A. \& R. H. Egdahl. 1962. Transformation of nonimmune lymph nodes cells to state of transplantation immunity by RNA. Ann. Surg. 156: 156-366.

9. Dvorak, H. F., A. B. T. U. Kosunen \& B. H. Waksman. 1963. The "transfer reaction" in the rabbit. Lab. Invest. 12: 58-68.

10. Ramseier, H. \& R. E. Billingham. 1964. Delayed hypersensitivity reactions and transplantation immunity in Syrian hamsters. Ann. N.Y. Acad. Sci. 120: 379-392.

11. Ramseier, H. \& J. W. Streilein. 1965. Homograft sensitivity reactions in irradiated hamsters. Lancet 1: 622-624.

12. RAmSeier, H. \& R. E. Bil.lingham. 1966. Studies on delayed cutaneous inflammatory reactions elicited by inoculation of homologous cells into hamsters' skin. J. Exp. Med. 123: 629-656.

13. Streilein, J. W. \& R. E. Billingham. 1967. Cutaneous hypersensitivity reactions to cellular isoantigens in rats. J. Exp. Med. 126: 455-473.

14. Streilein, J. W. \& R. E. Billingham. 1970. An analysis of the genetic requirements for delayed cutaneous hypersensitivity reactions to transplantation antigens in mice. J. Exp. Med. 131: 409-427.

15. Streilein, J. W., I. Zeiss \& D. Steinmuller. 1970. Studies on immune lymphocyte transfer reactions in murine homologous cell chimeras. Transplantation 10: 403-410.

16. StreILEIN, J. W. \& C. F. BARKER. 1966. Transplantation immunity and delayed cutaneous hypersensitivity reactions in dogs. J. Immunol. 98: 601-608.

17. Sternmuli.er, D. 1985. Which T cells mediate allograft rejection? Transplantation 40: 229-233.

18. MASON, D. W. \& P. J. Morris. 1986. Effector mechanisms in allograft rejection. Annu. Rev. Immunol. 4: 119-45.

19. Snider, M. E. \& D. Steinmuller. 1987. Nonspecific tissue destruction as a consequence of cytotoxic T lymphocyte interaction with antigen-specific target cells. Transplant. Proc. 19: 421-423.

20. Burlingham, W. J., M. E. Snider, J. D. Tyler \& D. Steinmuller. 1984. Lysis of mouse macrophages, fibroblasts and epidermal cells by epidermal alloantigen-specific CTL. Effect of culture and inflammatory agents on Epa-1 expression. Cell. Immunol. 87: 553-565.

21. MarX, R., K. Dalziel \& P. J. Dykes. 1984. Inflammation caused by intracutaneous implantation of stratum corneum. Br. J. Dermatol. 27, Suppl. 3: 109-113.

22. Simpson, E. 1984. H-2 and non-H-2 Ir genes. Ann. Immunol. 135C: $410-413$.

23. Kon, N. D. \& P. A. KLEIN. 1976. Measurement of H-2 and non-H-2 antigens in the mouse with the footpad swelling test. J. Immunol. 117: 413-415.

24. SMrTH, F. I. \& J. F. A. P. MilleR. 1979. Delayed-type hypersensitivity to allogeneic cells in mice. III. Sensitivity to cell-surface antigens coded by the major histocompatibility complex and by other genes. J. Exp. Med. 150: 965-976.

25. La Rosa, G. \& D. W. TAlmage. 1985. Synergism between minor and major histocompatibility antigens in the rejection of cultured allografts. Transplantation 39: 480485 .

26. Ohori, P., S. Nadal \& J. F. Burdick, 1983. Strong stimulation of two aspects of delayed-type hypersensitivity by minor antigens. Transplantation 36: 581-583.

27. Burdick, J. F. 1986. Strong cellular immune response induced in vivo against minor antigens in the mouse. Immunology 58: 615-620.

28. Steinmuller, D., M. E. Snider, R. L. Noble, H. F. Maassab \& S. J. Galli. 1987. Nonspecific tissue destruction resulting from cytotoxic $\mathrm{T}$ cell-target cell interactions. Manuscript in preparation.

29. ROBERTSON, M. 1986. T-cell receptor: gamma gene product surfaces. Nature (London) 322: $110-111$.

30. Steinmuller, D., J. D. Tyler \& C. S. David. 1981. Cell-mediated cytotoxicity to non-MHC alloantigens on mouse epidermal cells. I. H-2 restricted reactions among strains sharing the $\mathrm{H}-2^{\mathrm{k}}$ haplotype. J. Immunol. 126: 1747-1753. 
31. Steinmuller, D., J. D. Tyler \& A. R. Zinsmeister. 1985. Strain distribution of the new tissue-restricted alloantigen Epa-1. Transplant. Proc. 17: 749-753.

32. Van Loveren, H., K. Kato, R. Meade, R. Green, M. Horowitz, W. Ptak \& P. W. Askenase. 1984. Characterization of two different $L y-1^{+} \mathrm{T}$ cell populations that mediate delayed-type hypersensitivity. J. Immunol. 133: 4202-4211.

33. BRetscher. P. A. 1986. A cascade of T-T interactions, mediated by the linked recognition of antigen, in the induction of T cells able to help delayed-type hypersensitivity responses. J. Immunol. 137: 3726-3735.

34. Cobbold, S. \& H. Waldmann. 1986. Skin allograft rejection by $\mathrm{L} 3 / \mathrm{T}^{+}$and $\mathrm{Lyt}-2^{+} \mathrm{T}$ cell subsets. Transplantation 41: 634-639.

35. Gurley, K. E. B. M. Hall \& S. E. Dorsch. 1986. "The factor of immunization" in allograft rejection: carried by cytotoxic $T$ cells. not helper-inducer $T$ cells. Transplant. Proc. 18: 307-309.

36. MintZ, B. \& W. K. Sil vers. 1970. Histocompatibility antigens on melanoblasts and hair follicle cells. Cell-localized homograft rejection in allophenic skin grafts. Transplantation 9: 497-505.

37. Dvorak, H. F., M. C. Mihm. A. M. Dvorak, B, A. Barnes, E. J. Manseau \& S. J. GAlLI. 1979. Rejection of first-set skin allografts in man. The microvasculature is the critical target of the immune response. J. Exp. Med. 150: 322-337.

38. Stuart. F. P.. E. Bastien, A. Holter. F. W. Fitch \& W. L. Elkins. 1971. Role of passenger leukocytes in the rejection of renal allografts. Transplant. Proc. 3: 461464.

39. Streilein, J. W. 1972. Pathologic lesions of GVH disease in hamsters: Antigenic target versus "innocent bystander." Prog. Exp. Tumor Res. 16: 396-408.

40. Elkins. W. L. \& R. D. GutTManN. 1968. Pathogenesis of a local graft versus host reaction: immunogenicity of circulating host leukocytes. Science 159: 1250-1251.

41. Elson, C. O., R. W. Reilly \& I. H. Rosenberg. 1977. Small intestinal injury in the graft versus host reaction: an innocent bystander phenomenon. Gastroenterology 72: 886-889.

42. Mowat, A. MCI. 1986. Evidence that $\mathrm{Ia}^{-}$bone-marrow-derived cells are the stimulus for the intestinal phase of the murine graft-versus-host reaction. Transplantation 42: $141-143$.

43. WaKsman, Byron H. 1962. Tissue damage in the "delayed" (cellular) type of hypersensitivity. In Mechanisms of Cell and Tissue Damage Produced by Immune Reactions (Second International Symposium on Immunopathology). B. Schwabe, Ed. 154-166. Grune \& Stratton. New York.

44. Holoshitz, J.. Y. Naparstek. A. Ben-Nun, P. Marquardt \& I. R. Cohen. 1984. T lymphocyte lines induce autoimmune encephalomyelitis. delayed hypersensitivity and bystander encephalitis or arthritis. Eur. J. Immunol. 14: 729-734.

45. Nifderkorn, J. Y.. J. A. Shadduck \& J. W. Streilein. 1981. Immunogenetic basis of immunologic privilege in the anterior chamber of the eye. Immunogenetics 13: $227-236$.

46. Knisely, T. L., M. W. Luckenbach. B. J. Fischer \& J. Y. Niederkorn. 1987. Destructive and nondestructive patterns of immune rejection of syngeneic intraocular tumors. J. Immunol. 138: 4515-4523.

47. Galli, S. J., R. C. Bast JR., B. S. Bast, T. Isomura, B. Zbar, H. J. Rapp \& H. F. DVORAK. 1982. Bystander suppression of tumor growth: Evidence that specific targets and bystanders are damaged by injury to a common microvasculature. J. Immunol. 129: 1790-1799.

48. Rubin, R. H. \& N. E. Tolkoff-Rubin. 1984. The problem of cytomegalovirus infection in transplantation. Prog. Transplant. 1: 89-114. 